\title{
INCAÍSMO Y LEGITIMACIÓN DE LA "NACIÓN" AMERICANA EN EL DIÁLOGO ENTRE ATAHUALPA Y FERNANDO VII EN LOS CAMPOS ELÍSEOS
}

\author{
Incaism and Legitimation of the American "Nation" in the Diálogo entre Atahualpa y \\ Fernando VII en los Campos Elíseos
}

\section{Gustavo V. García*}

\begin{abstract}
RESUMEN
El Diálogo entre Atahualpa y Fernando VII en los Campos Elíseos [1809] de Bernardo Monteagudo reclama la independencia americana del dominio español. Su claridad y radicalidad no derivan de un criterio teleológico de pensar y construir la "nación" como algo completamente elaborado desde los inicios de los movimientos independentistas. Al contrario, el Diálogo es fruto de las experiencias históricas y la construcción simbólica de una nueva identidad propuesta por el incaísmo que se consolidó a fines del siglo XVIII y principios del XIX, como la primera doctrina política emancipadora de alcance continental. El incaísmo tenía una recepción favorable en distintos sectores sometidos a la dominación española. Para las masas indígenas (y populares) representaba la oportunidad de una redención racial. Y, para los letrados — a través de la lectura e interpretación de Comentarios reales de los incas - ofrecía la posibilidad de "retornar" y construir una "nación" americana actualizando la tradición incaica con la ilustración europea.
\end{abstract}

Palabras clave: Bernardo Monteagudo, independencia latinoamericana, Charcas, Bolivia, Atahualpa, Fernando VII, literatura colonial.

\begin{abstract}
The Diálogo entre Atahualpa y Fernando VII en los Campos Elíseos of Bernardo Monteagudo claims independence of the Americas from Spanish domination. Its clarity and radicalism are not derived from a teleological-based criterion of thinking and building the "nation" as something completely shaped since the beginings of the independence movements. On the contrary, the Diálogo is the outcome of the historical experiences and the symbolic construction of a new identity proposed by the "Inca-ism" that was consolidated, at the end of the 18th century and the beginning of the 19th, as the first political emancipation doctrine with continental reach. The "Inca-ism" had a favorable reception with different sectors that had been under Spanish domination. For the indigenous (and popular) masses this represented the oportunity of a racial redemption. On the part of the intellectuals, through reading and interpretation of The Royal Commentaries of the Incas offered the possibility to "return" and construct an American "Nation" modernizing the Incan tradition by the influence of the European Enlightenment.

Key Words: Bernardo Monteagudo, Latin American independence, Charcas, Bolivia, Atahualpa, Ferdinand VII, Latin American Colonial Literature.
\end{abstract}

Rose-Hulman Institute of Technology. Profesor de español. Estados Unidos de América.

Correo electrónico: gustavo.garcia@rose-hulman.edu

Recepción: 14/2/17. Aceptación: 23/3/17. 


\section{Introducción}

El proceso de la emancipación hispanoamericana ha sido estudiado desde múltiples perspectivas y planteamientos teóricos. Una de las más aceptadas la considera producto de la crisis de transformación económica, política y cultural que experimentaba Europa desde el siglo XVIII. Aunque el contexto externo es innegable, el proceso - arduo y complejo- también fue motivado por factores internos como la implantación de las reformas borbónicas que pretendían mejorar la eficiencia tributaria en las colonias. Pero ocurrió otra cosa. Las reformas profundizaron el descontento de todos. La minoría criolla vio disminuir su influencia y poder por la reducción de sus cargos administrativos; y, por el aumento de impuestos y tributos, los mestizos e indígenas se empobrecieron más. Hay, empero, otro factor no menos importante que el económico. Se trata de una tradición ideológica propia que — de forma vaga e imprecisa - se consolida en el imaginario popular como "Americana" pese a gestarse en torno a múltiples movimientos locales de resistencia al poder colonial:

[...] el proceso de la Emancipación se desata en tierra americana a partir de situaciones locales y desencadena una dinámica propia que no se puede reducir a la que es peculiar de los procesos europeos contemporáneos. Más aún: desencadena también unas corrientes de ideas estrictamente arraigadas a aquellas situaciones que, aunque vagamente formuladas y carentes de precisión conceptual, orientan el comportamiento social y político de las minorías dirigentes y de los nuevos sectores populares indicando los objetivos de la acción, el sentido de las decisiones y los caracteres de las respuestas ofrecidas a las antiguas y a las nuevas situaciones locales (Romero, 1977: IX).

La aspiración común de estos primeros movimientos libertarios locales justificaba, por encima de sus especificidades, la construcción y emergencia de un vasto espacio simbólico que pudiera oponerse y reemplazar a España. El previsible "vacío" político y jurídico que implicaba la liquidación del sistema colonial tenía que ser llenado con un imaginario tan grande como la "madre patria": América. Tampoco ocurrió así. El proyecto ideal y atractivo de la Nación-americana fue derrotado en la práctica por la emergencia del Estado-nación. Por eso, con la consolidación militar y política de la independencia, la propuesta americanista por su ambigüedad entre otras razones - se fragmenta en varias nacionalidades. Si en un pasado "glorioso" los próceres y guerrilleros patriotas hablaban, debatían, escribían y peleaban en nombre de "América" (la patria); en el presente republicano sus herederos y administradores lugareños se consolidan como argentinos, bolivianos, chilenos o peruanos.

En este ensayo exploro la influencia del incaísmo, la primera utopía fundadora de una identidad "americana" en el Diálogo entre Atahualpa y Fernando VII en los Campos Elíseos [1809] atribuido a Bernardo Monteagudo en 1809 , texto que reclama, de forma clara y radical, la independencia del dominio español. El incaísmo, por tener su origen en la idealización del imperio de los incas, no estaba restringido por obstáculos regionales ni reordenamientos territoriales conflictivos. Su recepción favorable en distintos sectores sometidos a la dominación peninsular determinó que su éxito fuera tal que incluso lo aceptaron en regiones donde el imperio incaico fue resistido ${ }^{1}$ o no había llegado: Buenos Aires y las "Provincias Unidas de Sudamérica".

\section{El Incaísmo}

El incaísmo alcanzó su máxima influencia a nivel político y literario a inicios del siglo XIX ${ }^{2}$, en el período de las revoluciones independentistas y los primeros años de vida republicana de los países andinos y en la zona del Río de la Plata $^{3}$. Su atractivo, incluso ahora, consiste en ser el primer "nacionalismo global" antes de que se consumara la independencia ${ }^{4}$. Para sus adeptos, el origen de la "patria americana" se remonta hasta antes de la llegada de los conquistadores, encomenderos y funcionarios peninsulares. Sin embargo, al excluir al "otro" colonial, el intento inclusivo de "homogeneizar" lo americano es una prolongación ficticia de otra 
no menos ficticia construcción: la nostálgica visión idealizada del imperio Inca.

Esta doctrina de plantear (y resolver) el conflicto colonial en términos de dos "naciones" adversarias tiene un componente híbrido porque además de la fabulación popular mítica del Tahuantinsuyo, se nutre de los Comentarios reales de los Incas [1609] del Inca Garcilaso de la Vega ${ }^{5}$ y de la "leyenda negra" de España popularizada por Bartolomé de Las Casas.

El incaísmo, tanto en su vertiente histórica (la revolución de Huarochirí, 1750; las rebeliones de Túpac Amaru II y Túpac Katari, 1780-1781), como en la simbólica (Comentarios reales, Tragedia del fin de Atahualpa, el folklore andino, y los mitos del Taky Ongoy y de Inkarri), construye y prolonga un espacio cultural asociado por razones prácticas e ideológicas a lo "americano": el imperio incaico. Este es el elemento indispensable para legitimar la autodeterminación de los pueblos "originarios" (en realidad mestizos que subsumen al estamento indígena) como sucesores de los incas opuestos al "desgobierno y tiranía" de los españoles. Se plantea, entonces, una ruptura política e histórica que es, a la vez, un entronque que intenta continuar y prolongar una imaginaria y conflictiva "historia patria", excluyendo a los "godos", "gachupines" o "chapetones" (extranjeros), pero sin incluir a los "indios" a los "pardos" o a los "morenos".

El incaísmo tenía una recepción favorable en distintos sectores sometidos a la dominación peninsular. Para las masas de indígenas (y mestizos postergados) representaba la posibilidad de una redención racial (ensayada por los levantamientos indígenas de fines del siglo XVIII). Estas numerosas rebeliones fueron conocidas y tuvieron un importante respaldo ideológico a través de los pasquines — “papeles ciegos" según el visitador José Antonio de Areche Zornoza- cuya función comunicativa evoluciona de una crítica velada a un abierto desconocimiento del orden colonial ${ }^{6}$. Boleslao Lewin transcribe algunos pasquines radicales que manifiestan el descontento popular contra las autoridades y representantes de la corona. El que apareció en La Paz el 4 de marzo de 1780, a pesar de no tener una orientación incaísta, es uno de los más subversivos:

Viva la ley de Dios y la puresa de María, y Muera
el Rey de España, y seacabe el Perú, pues el
es causa de tanta enequidad; Si el monarca no
sabe de las insolencias de sus ministros de los
Robos Públicos, y como tienen ostilisados a los
pobres Viba el Rey y mueran todos estos ladrones
públicos, ya que no quieren poner enmienda enlo
que se les pide. Con esta ban dos habisos, y no ay
enmienda pues lloraremos detal lastima por qe.
por dos o tres malignos ladrones que estan aqui
pagaran muchos, ynocentes y correra sangre por
calles y Plasa cuanta Agua lleban las Calles de
la Paz; cuenta el q.e no defiende alos criollos.
(Énfasis mío) (Lewin, 1943: 57).

El autor, aunque todavía dubitativo, abandona la fórmula diplomática de “iViva el Rey y muera el mal gobierno!” para entrar en una abierta rebelión contra el monarca y sus malos funcionarios: propone su fin pero no señala ninguna alternativa de gobierno. Más radical y preciso es el pasquín incaísta que apareció en Oruro a principios de abril de 1781:

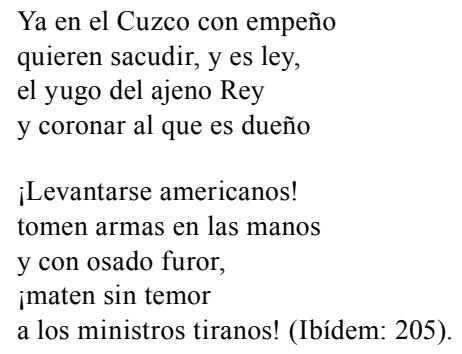

El mensaje, aludiendo a la sublevación de Túpac Amaru (noviembre de 1780), construye una "nacionalidad" americana basada en la legitimidad incaica e incita a poner fin al régimen peninsular porque es "ajeno". Estos escritos anónimos, con ligeras variantes, aparecieron en las principales ciudades del virreinato del Perú contribuyendo a forjar una conciencia en las masas coloniales de pertenecer a una nación vagamente uniforme pero diferente de la española: los "americanos" o "indianos" se creían descendientes de los incas y, por tanto, tenían que defender sus derechos rectificando la historia. La justicia —ética y jurídicaconsistía en reemplazar al soberano ajeno por 
el verdadero tal cual propone este pasquín que apareció el 22 de marzo de 1782 en la puerta de la Real Audiencia de Charcas:

\author{
El General Inca viva. \\ Juremosle ya p.r Rey; \\ por que es mui justo, y de ley \\ que lo que es suyo reciva. \\ Todo indiano se aperciva \\ a defender su derecho \\ por que Carlos con despecho \\ los aniquila, y despluma, \\ $\mathrm{y}$ viene a ser todo en suma, \\ robo al revés y al derecho \\ Tanto daño penetrado \\ Vengarse a gusto cumplido \\ Pues españoles han sido \\ Autores del mal causado \\ Morirán con el Soldado \\ Alcaldes, Corregidores \\ Ricos, pobres y Oydores, \\ O no he de ser Tupac Amaro (Ibídem: 206).
}

Para este pasquín, que se atribuye la autoría de Túpac Amaru, el rey de España identificado claramente con su nombre- es el usurpador que tiene que ser reemplazado por el descendiente directo del legítimo Sapa Inca. La propaganda ideológica es innegable: los "indianos", aceptando al "general inca" como "rey" deben defender sus derechos y exterminar a los peninsulares sin distinción alguna: ricos o pobres, soldados o funcionarios de alto rango. El conflicto no se plantea en torno a posturas ideológicas a favor o en contra de la independencia sino en términos raciales irreconciliables: "indianos" (buenos o malos) versus "españoles" (malos o buenos). La emancipación, se implica, no solo es justa sino necesaria para (re)ordenar el mundo. Estas propuestas concretas de expulsar a los españoles fortalecen la idea — vaga e imprecisa - de una comunidad imaginada ${ }^{7}$ : una nación americana construida social, racial y políticamente por quienes se percibían como descendientes y herederos del "imperio de los cuatro confines". Asimismo, en la vida social cotidiana, los pasquines - hojas "habladoras" que vuelan de ciudad en ciudad - reemplazan (porque quieren cumplir) la profecía de Inkarri. Este mito del
Inca-Rey es uno de los más famosos en el área andina. Su origen se remonta a la ejecución de Atahualpa por Españarri (España-Rey). Pero Inkarri habría prometido volver un día para vengar su muerte y la suerte de sus súbditos. Según la leyenda, los conquistadores enterraron su cuerpo en diversos lugares del Perú: su cabeza en el palacio presidencial de Lima, sus brazos en Waqaypata (la plaza de las lágrimas en el Cuzco) y sus piernas en algún lugar de Ayacucho (el rincón de los muertos). La cabeza de Inkarri, sin embargo, está regenerando en secreto su cuerpo para volver y restaurar el Tahuantinsuyo y el orden del mundo quebrado por la invasión castellana.

El incaísmo, para los criollos y mestizos letrados, ofrecía a través de la lectura e interpretación de Comentarios reales de los incas la posibilidad de "retornar", prolongar y, sobre todo, construir una "nación" americana legitimando la tradición incaica sazonada por la ilustración europea progresista (en especial El contrato social y las ideas de John Locke, Thomas Hobbes y Montesquieu). Para estos estratos sociales la hibridez del incaísmo parecía ser un entronque sincrónico de lo antiguo con lo nuevo. La finalidad práctica, no obstante, era menos idealista: reemplazar a los peninsulares en el dominio de la administración pública, dejando que los indígenas - descendientes directos de los incas - sigan siendo "indios" (sujetos subalternos). Así el pasado incaico no era el modelo al que se pretendía volver sino un pretexto para legitimar los intereses de los nuevos estamentos emergentes.

El Diálogo entre Atahualpa y Fernando VII en los Campos Elíseos [1809] atribuido a Bernardo Monteagudo "el genio sombrío de la revolución americana" según Galván Moreno $(1950)^{8}$, es un texto clave que además de ilustrar la siempre conflictiva y productiva relación entre literatura y política en la entonces Real Audiencia de Charcas, recoge y continúa una rica, aunque velada tradición incaísta entre intelectuales progresistas de la Universidad de San Francisco Xavier y la Academia Carolina de Charcas en la actual ciudad de Sucre en Bolivia9. 


\section{Patria y Nación en el contexto colonial}

Antes de analizar este fascinante escrito literario-filosófico-político conviene precisar los conceptos de patria y nación en el contexto colonial. Las definiciones provenían de diccionarios peninsulares. En el Tesoro de la lengua castellana [1611], Sebastián Covarrubias establece que patria es: "La tierra donde vno ha nacido". El Diccionario de autoridades [1726-1739] confirma y especifica este término como: "El Lugar, Ciudad o País en que se ha nacido". Patria, por consiguiente, es indisoluble del lugar de nacimiento; y, por eso, define una identidad de lealtad asociada en principio a un espacio local pero que puede ser parte de una organización territorial más extensa: "Como un sentimiento moral la patria tiene un sentido de solidaridad con la familia, la sociedad local y el lugar. Respecto al lugar este tipo de lealtad territorializada podía ser una aldea, una ciudad, una provincia, un reino o un imperio" (Díaz Caballero, 2004: 83).

Nación era un concepto más ambiguo. En algunas definiciones se infiere a un contenido territorial, étnico, cultural e institucional asociado a una colectividad con una lengua, historia, leyes y lenguas comunes: "Reyno, o Prouincia estédida, como la nacion Española" (Covarrubias-Orozco, 1911). El Diccionario de autoridades ofrece tres acepciones. La primera incluye a cualquier ser humano porque tiene que ver con: "El acto de nacer. En este sentido, se usa en el modo de hablar De nación, en lugar de Nacimiento: y assí dicen, Ciego de nación. Latín. Nativitas". La segunda, influida por el derecho romano, se amplia a: "La colección de los habitadores en alguna Provincia, Pais o Reino. Latín. Natio. Gens. FR. L. DE GRAN. Symb. part. 1. cap. 3. Con ser tantas y tan varias las naciones del mundo. ERCILL. Arauc. Cant. 12. Oct. 45. Pero tan grande crédito alcanzaba,/ Que toda la Nación le respetaba". Para esta explicación todo habitante de un espacio geográfico pertenece a la nación sin importar su origen, su religión, su idioma o sus costumbres $\mathrm{y}$ tradiciones. La tercera definición entra en contradicción con la segunda al precisar que: "Se usa freqüentemente para significar qualquier Extrangero. Es del estilo baxo. Latín. Exterae gentis homo". Hobsbawm (1991) reconoce la dualidad de este significado: "Antes de 1884, la palabra nación significaba sencillamente «la colección de los habitantes en alguna provincia, país o reino» y también «extranjero»" (p.11). Esta ambigüedad conceptual se acentúa a principios del siglo XIX con la consolidación de nuevos estados independientes de España que enfrentan problemas epistemológicos:

¿Pero de qué nación se trata? El término se presta en
esa época a una exaltación no exenta de ambigüedad,
pues remite tanto a una comunidad humana singular
como a un nuevo tipo de comunidad política, a un
pueblo de individuos-ciudadanos. En esa época
ninguno de los sentidos del término puede predicar
con certeza las realidades latinoamericanas. ¿Con
qué se identifica la nación soberana? ¿Con las
divisiones administrativas de la Corona, con las
ciudades, con los reinos, con el conjunto de la
América hispánica o portuguesa? ¿Cuál es el
sujeto último de la soberanía: la nación o los
pueblos? ¿Quiénes son los ciudadanos sobre los que
reposa el ejercicio de la soberanía: las élites o el
conjunto de la población? Buena parte de la historia
latinoamericana contemporánea lleva la marca
de los conflictos provocados por esas soberanías
rivales. Sólo el Brasil escapa a la fragmentación
política mientras que la América hispánica estalla
en una pluralidad de estados (Guerra, 2003: 10).

La imprecisión y vaguedad de "nación" justificaba, incluso entre las capas intelectuales, la "justeza" de la lucha por la independencia "americana" localizada en regiones unidas por un imaginario común: el imperio incaico. Era suficiente y más conveniente "saber" así fuese vagamente - por qué y para qué se luchaba ("América" o "patria") que precisar los alcances o limitaciones de un término de por sí conflictivo e imposible de clasificar. En efecto, "nación" es un concepto tan resbaladizo que muchas veces se confunde con "Estado" o con un grupo étnico ${ }^{10}$. Lo único seguro es que, al igual que la "novela", es una idea inacabada: en proceso de construcción. Su imprecisión, empero, le otorga una característica proteica que se contradice consigo misma: "se trata de un ente que es teórico y estético, orgánico 
y artificial, individual y colectivo, universal y particular, independiente y dependiente, ideológico y apolítico, trascendente y funcional, étnico y cívico, continuo y discontinuo" (Delannoi, 1993: 9).

En el contexto geopolítico colonial la ambigüedad de "nación" o "patria" era una virtud. Más que discrepancias o parecidos conceptuales, estos términos evocaban usos muchas veces complementarios, aunque ideológicamente variables que borraban y ampliaban las fronteras geográficas de los movimientos emancipatorios. De acuerdo con las circunstancias, la "patria" en el Alto Perú, por ejemplo, era Perú o la Junta de Buenos Aires.

En las primeras páginas de Comentarios reales, el texto canónico del incaísmo, la patria es el espacio reducido a la ciudad del Cuzco. En el "Proemio al lector", Garcilaso, el inca letrado (en realidad uno de los primeros mestizos de América), informa que escribió su obra: "como natural de la ciudad del Cuzco, que fue otra Roma en aquel Imperio [...] forzado del amor natural de la patria [...]" (Vega, 1991, I: 5). Pero, en otros pasajes, también es el inmenso territorio del Tahuantinsuyo y, simbólicamente, "las cuatro partes del mundo": "mi patria (yo llamo así a todo el imperio que fue de los Incas)" (Ibídem, II, XXIV: 254). Patria, por lo visto, tiene una vocación "universalista": del Cuzco (el ombligo de la tierra) se extiende al imperio Inca y a las cuatro partes del mundo (Tahuantinsuyo). Esta visión totalizante es comprensible si se tiene en cuenta la constante expansión imperial incaica.

El Inca Garcilaso, asimismo, emplea el vocablo "nación" de manera vaga e imprecisa de acuerdo con sus propias definiciones. Algunas veces le otorga un sentido territorial identificado con Perú: "[...] no hubo confesiones secretas en los indios (hablo de los del Perú y no me entrometo en otras naciones, reinos o provincias que no conozco)" (Ibídem, I, XIII: 87). Pero en otros pasajes infiere un sentido institucional asociado al imperio de los incas (descripción de costumbres y leyes, forma de gobierno y organización social). "Nación" también posee connotaciones étnicas en un doble sentido. El primero tiene un carácter globalizador cuando
Garcilaso la extiende a otras naciones sometidas al Tahuantinsuyo, es decir, gente diferente que "goza" de las bondades del régimen cuzqueño ${ }^{11}$. El segundo sentido es para resaltar y diferenciar al imperio incaico de otras naciones indígenas "bárbaras" o "paganas", aspecto necesario para justificar la legitimidad "civilizadora" (otra Roma) de los incas. De los numerosos ejemplos que respaldan esta interpretación señalo el que se refiere a la "grande provincia llamada Chirihuana, que está en los Antis, al levante de los Charcas". Garcilaso narra que el Inca Cápac Yupanqui, antes de emprender su labor de conquista, envía espías que:

[...] volvieron diciendo que [...] los naturales eran brutísimos, peores que bestias fieras; que no tenían religión ni adoraban cosa alguna; que vivían sin ley ni buena costumbre, sino como animales por las montañas, sin pueblos ni casas, y que comían carne humana, y, para la haber, salían a saltear las provincias comarcanas y comían todos los que prendían, sin respetar sexo ni edad, y bebían la sangre cuando los degollaban, porque no se les perdiese nada de la presa. Y que no solamente comían la carne de los comarcanos que prendían, sino también la de los suyos propios cuando se morían; y que después de habérselos comido, les volvían a juntar los huesos por sus coyunturas, y los lloraban y los enterraban en resquicios de peñas o huecos de árboles, y que andaban en cueros y que para juntarse en el coito no se tenía cuenta con las hermanas, hijas ni madres. Y que ésta era la común manera de vivir de la nación Chirihuana (Ibídem, II, XVII: 122-123).

Alarmado por esta falta de "ley" y "buena costumbre", el soberano "poderoso y memorable"12 recuerda a sus súbditos la "obligación", por mandato divino, de civilizar a otras naciones: "Ahora es mayor y más forzosa la obligación que tenemos de conquistar los Chirihuanas, para sacarlos de las torpezas y bestialidades en que viven y reducirlos a vida de hombres, pues para eso nos envía nuestro padre el Sol" (Ibídem, II, XVII: 123).

Este rol expansionista de los incas, que para Garcilaso se justifica por sus efectos "civilizadores", también tiene, en otros trozos textuales, connotaciones institucionales de orden político-jurídico. Cito un ejemplo referido a la región que, según él, llaman "Charca". De 
acuerdo al inca letrado, allí: "se encierran muchas provincias de diferentes naciones y lenguas, y todas ellas son del distrito Collasuyu" (Ibídem, I, XVII: 157). Ante la presencia de Cápac Yupanqui que seguía en afanes de expandir su imperio:

Aquellas naciones, que ya sabían lo que había pasado en Chayanta, respondieron todas casi unas mismas razones, con poca diferencia de unas a otras: en suma, dijeron que se tenían por dichosas de adorar al Sol y de tener por señor al Inca, su hijo; que ya tenían noticia de sus leyes y buen gobierno; le suplicaban los recibiese debajo de su amparo, que le ofrecían sus vidas y haciendas; que mandase conquistar y allanar las demás naciones circunvecinas a ellos porque no les hiciesen guerra y maltratasen por haber desechado sus ídolos antiguos y tomado nueva religión y nuevas leyes (Ibídem, I, XVII: 158).

La explicación, un buen ejemplo de la propaganda imperial cuzqueña, muestra un razonamiento que tendría implicaciones futuras contundentes: la voluntad política para el Inca Garcilaso (y sus lectores independentistas) reside en la "nación" (el pueblo) que puede y debe elegir su religión y "buen gobierno" de manera libre y soberana. Bernardo Monteagudo y otros próceres de la emancipación reconocen en este tipo de exposiciones una coincidencia ideológica con la "biblia política" de entonces: El contrato social de Jean-Jacques Rousseau (1980) que postula la libertad e igualdad de los hombres bajo un Estado sujeto a un "contrato social" basado en la voluntad general.

Estas lecturas, unidas a sucesos históricos de resistencia al poder colonial, forjaron $y$ reforzaron un imaginario "incaísta" enraizado en el concepto estereotipado del "buen salvaje" y la gloria del imperio de los incas (lo americano) sujeto a un sistema político de un "mejor gobierno" (lo europeo no-español). La hibridez entre evocaciones del pasado imperial incaico y las ideas progresistas de Europa también influyó en el uso de los conceptos de patria y nación en los primeros movimientos libertarios. La patria es el espacio local de nacimiento que puede, según intereses locales, transformarse en "américa", un vago espacio pequeño o grande opuesto al poder colonial; en tanto que nación es el territorio identificado con "América" (la grande): el imperio no solo geográfico de los Incas (limitado históricamente a Perú, Ecuador y partes de Argentina, Bolivia, Chile y Colombia) sino el espacio simbólico del Tahuantinsuyu que abarcaba las cuatro partes del mundo además de territorios localizados en el reino de la imaginación. El 6 de abril de 1781, por ejemplo, se encontró en los baúles de Túpac Amaru un bando en cuyo encabezamiento se lee:

D. José I, por la gracia de Dios Inca, Rey del Perú, Santa Fé, Quito, Chile, Buenos Aires, y continentes de los mares del sud, duque de la Superlativa, Señor de los Césares y Amazonas con dominio en el gran Paitití, Comisario distribuidor de la piedad divina por erario sin par, etc. (Lewin, 1943: 202).

Esta flexibilidad conceptual construye una nueva "gloriosa patria común" que además de continuar la historia incaica, rivaliza con el imperio español y, lo más importante, puede reemplazarlo llenando el vacío político, cultural y social del orden colonial. La bandera de "América", que proporcionó a las masas una agenda común en la que podían reconocerse (y refugiarse), explica que los primeros intentos emancipatorios se hayan hecho en nombre de la "patria americana": la utopía contemporánea capaz de oponerse no solo a España, sino también a Europa o a los Estados Unidos.

\section{El diálogo (im)posible de dos monarcas letrados}

El Diálogo entre Atahualpa y Fernando VII, a través de una hipotética conversación filosófica-política entre Atahualpa ${ }^{13}$ y Fernando $\mathrm{VII}^{14}$, se inserta en el contexto político y social de la época y justifica el derecho de autodeterminación de los "herederos" del imperio incaico (lo "americano") frente a la usurpación de los peninsulares (lo "extranjero"). De acuerdo con Francovich el Diálogo es:

[...] un poderoso elemento de subversión, ya que interpretaba con admirable acuidad, gran acopio de doctrina y con una ardiente elocuencia la emoción política de esos momentos.

El diálogo [...] era de una audacia excepcional. Sólo una personalidad con una ideología perfectamente 
definida y con una temeridad juvenil podía haberse atrevido a escribirlo (1948: 82).

La importancia del Diálogo fue inmensa para los movimientos independentistas de Argentina (Buenos Aires) y Bolivia (Chuquisaca, La Paz y Cochabamba). Su tesis central quebrar la esclavitud de la patria americanaes más radical que el famoso silogismo de Charcas que plantea y resuelve jurídicamente la independencia de las colonias americanas: ¿Se debe seguir el destino de España (invadida y sometida por Francia) o resistir en América? Las Indias son un dominio personal del rey de España; el rey está impedido de reinar; por lo tanto las Indias deben gobernarse a sí mismas ${ }^{15}$.

La claridad y radicalidad del Diálogo no derivan, sin embargo, de un criterio teleológico de pensar y construir la "nación" como un concepto inmediatamente deseable y ya elaborado a inicios de los movimientos independentistas. Al contrario, el Diálogo es fruto de las experiencias históricas y la construcción simbólica de una nueva identidad propuesta por el incaísmo que se consolidó, a fines del siglo XVIII y principios del XIX, como la primera doctrina política emancipadora de alcance continental.

La elección de los interlocutores y el espacio del Diálogo no es fortuita. Primero, además de representar "naciones" antagónicas por excelencia: "América" frente a España, los personajes son reconocidos por cualquier persona culta de la época. Segundo, el diálogo (im)posible entre Atahualpa (muerto en 1532) y Fernando VII (todavía vivo en 1809) ocurre en los Campos Elíseos, espacio necesario e indispensable porque resuelve cualquier tipo de anacronismo y garantiza la neutralidad del "campo de juego". En efecto, en este lugar paradisíaco del Hades (inframundo) pueden coexistir ambos monarcas en igualdad de condiciones —en términos jurídicos y, sobre todo, culturales - puesto que es el sitio sagrado donde las "sombras" (almas) de las personas virtuosas gozan la eternidad de una existencia dichosa. El requisito de "igualdad de condiciones" es fundamental para el desarrollo del Diálogo. Ambos, Atahualpa y Fernando VII, al ser monarcas de sus respectivos dominios, son "hermanos" para el imaginario de la época, ya que los reyes, los "pastores" de los hombres, obtienen su poder por la gracia divina. Pero también - otro acierto clave del autor- son letrados que comparten un capital cultural que hace posible la dialéctica de las ideas. ${ }^{16}$ Los Campos Elíseos son, por otro lado, la referencia imprescindible para desarrollar los "diálogos de los muertos", un género literario muy importante hasta el siglo XVIII (Luciano de Samosata, Alfonso de Valdés, Francisco de Quevedo).

Luego de intercambiar fórmulas coloquiales que preparan el Diálogo, el Inca se apiada del joven "desgraciado" Fernando de Borbón ${ }^{17}$ y le informa, a su vez, de la injusticia cometida contra él: "Tus desdichas, tierno joven, me lastiman, tanto más cuanto por propia experiencia sé que es inmenso el dolor que padeces ya que yo también fui injustamente privado de un cetro y una corona" (Monteagudo, 1974: 56). El tema está definido: ambos, legítimos soberanos, son víctimas de una invasión extranjera: Francia y España respectivamente. Pero el Inca, además de sufrir la arbitrariedad de España, al comparar su situación con la de Fernando VII, inicia la tarea de aclarar, rectificar y prolongar su versión de la "historia americana" utilizando el discurso de un letrado. Acá es posible identificar una variante del "fetichismo de la escritura", actitud común entre los intelectuales indígenas que se oponían al régimen colonial. Es más, en su calidad de letrado, Atahualpa inserta un discurso autóctono precolombino (oral por excelencia) a la representación simbólica del poder hispano (la escritura). Se apropia, de este modo, de las armas del opresor. Explico este punto.

Cuando los españoles irrumpieron en América, no fue la imposición de un nuevo poder lo que causó la mayor extrañeza y sometimiento entre los indígenas. De acuerdo con Lienhard (1991: 3-9), los europeos repitieron, con diferencia de grado, las usurpaciones cometidas por los mayas, toltecas, aztecas e incas contra otros indígenas más débiles. Lo nuevo (y extraño) de la conquista fue la innovación impuesta para controlar la comunicación y la cultura: el uso de la escritura que, para los conquistadores, y con más misterio para los autóctonos, evocaba 
"mágicamente" la autoridad de los reyes, representantes del poder divino. No hay que olvidar el famoso "Requerimiento": en nombre del rey, y utilizando escritos legitimados por la presencia de un notario, los conquistadores tomaban posesión de las tierras de los indígenas. Este despojo "legal" se justificaba por la entrega de América a la corona castellana por parte del papado.

En la historia colonial de Latinoamérica el fetichismo escriturario se manifiesta en el "papel" del letrado, por lo general un funcionario que desempeña la labor de legitimar el control imperial sobre los colonizados que se sometían a la "magia" del discurso escrito. En efecto, la separación e independencia de la escritura y el opresivo aparato político colonial no fueron percibidos por indígenas letrados que identificaron al último como derivado de la primera:

En los no muy numerosos autores indígenas que surgen en los decenios consecutivos al primer contacto, se nota el impacto de ese núcleo ideológico: confiados en el poder del discurso escrito, indios nobles como el apenas mencionado Titu Cusi y Guamán Poma o los dignatarios mesoamericanos autores de títulos genealógicos y de cartas reivindicativas, parecen atribuir al mensaje escrito una eficacia intrínseca, independiente del aparato político que la sustenta (Lienhard, 1991: 11).

La percepción del poder excesivo de la escritura motivó que los escasos intelectuales indígenas, siguiendo el modelo europeo, tratasen de manejarla para presentar y hacer conocer su marginalidad, sus reclamos y derechos; y, por el solo hecho de "escribir", resolverlos: el monarca - creían- no sabía lo que ocurría en las Indias. El resultado de estos esfuerzos, aunque no intencional, es una práctica de resistencia que constituye el cuerpo teórico de una literatura alternativa, la cual, a partir de la segunda mitad del siglo XX, despierta y genera interpretaciones críticas que la contraponen al canon oficial ${ }^{18}$.

Monteagudo, al inventar un Atahualpa intelectual, define lo "americano" frente a lo “español" en igualdad de condiciones en el espacio jurídico de la eternidad donde los jueces —otro acierto argumental — son las propias víctimas y, sobre todo, los lectores charqueños. La intención propagandista del Diálogo es fundamentar el derecho legítimo de los americanos a obtener su independencia con argumentos que, aunque en la época eran considerados subversivos, no dejan de tener sentido común:

\begin{abstract}
¿No es cierto, di, Fernando, que siendo la base y único firme sustentáculo de una legión y bien fundada soberanía, la libre, espontánea y deliberada voluntad de los pueblos en la cesión de sus derechos, el que, atropellado este sagrado principio, consiguiese subyugar una nación y ascender al trono sin haber subido por este sagrado escalón, será en vez de Rey un tirano a quien las naciones darán siempre el epíteto y renombre de usurpador? Sin duda que confesarlo debes porque es el poderoso comprobante de la notoria injusticia del Emperador de los franceses (1974: 57-58).
\end{abstract}

El Atahualpa de Monteagudo conoce muy bien El contrato social: su alusión se refiere a la "soberanía" (el concepto de la "voluntad general") que también coincide con las descripciones del Inca Garcilaso de la Vega donde diversas "naciones" aceptan "voluntaria" y "pacíficamente" el bondadoso gobierno del imperio de los cuatro confines. Incaísmo e ilustración europea se combinan armónicamente en este tipo de pasajes donde un muerto discute con un vivo. Todo, por lo visto, es posible en los Campos Elíseos.

El Inca Atahualpa prosigue su alegato enfatizando la igualdad de "legitimidad" entre él y Fernando VII para luego criticar el mal comportamiento de los españoles:

[Los españoles] saben que los americanos son unos hombres tímidos y sencillos, pero advierten al mismo tiempo que, aunque incultos y salvajes, son muy pocos los misantrópicos, y que los más viven reunidos en sociedad; que tienen sus soberanos a quienes obedecen con amor, y que cumplen con puntualidad sus órdenes y decretos. Saben, en fin, que estos monarcas descienden igualmente que tú, de infinitos reyes, y que bajo de su dominio disfrutan perfectamente sus vasallos de una paz inalterable; pero como con sus ojos empapados en el ponzoñoso licor de la ambición, creen coronadas de oro y plata las cimas de las montañas, o a lo menos, depositados en el interior de aquéllas, interminables tesoros, como las mismas cabañas de los rústicos e 
inocentes indianos les parecen repletas de preciosos metales, y quieren apoderarse de todo y conseguirlo todo; protestan arruinar aquella desdichada gente y destruir a sus monarcas. "La razón nos dicta - dicen ellos - que éste es un atentado, y la religión nos enseña que es un sacrilegio, mas no hay otro medio para mitigar nuestra implacable codicia. Sofóquese pues la humanidad, la religión y la razón, y verifíquense nuestros designios". Y al momento empiezan a llover por todas partes la desolación, el terror y la muerte, bárbaras en todo, hábiles únicamente en apurar y aumentar la crueldad y la tiranía, arruinar del mismo modo las humildes chozas que los suntuosos palacios; por todas partes corren rios inmensos de sangre inocente; en todas partes se encuentran millares de cadáveres, desdichadas victimas de la ferocidad española. (Énfasis añadido) (Ibídem, 1974: 58-60).

Mostrar una sociedad americana precolombina basada en leyes y tradiciones similares a las de los europeos, es un caso de translatio studii: transferencia del saber de un lugar a otro. Esta estrategia, derivada de Comentarios reales donde el Cuzco es otra Roma, destruye el estereotipo de los conquistadores que justificaban sus atrocidades considerando a los nativos como gente sin cultura y organizaciones sociales ${ }^{19}$. También reitera la "leyenda negra" basada en las denuncias de Bartolomé de Las Casas y otros sacerdotes. Esta parte de su intervención tiene dos propósitos. Primero, quiere conmover a sus lectores para ganar adeptos a su causa; segundo, creo que lo central, "defiende" y "protege" a sus "hombres tímidos y sencillos", denunciando sus maltratos al monarca de los "feroces" españoles para que este los controle porque ese es el deber de los reyes en su calidad de "pastores" de hombres: velar por el bienestar material y espiritual de sus súbditos. En esta argumentación se nota una amenaza más velada que la del padre Las Casas: los españoles pueden, por sus pecados en América, ser castigados por la justicia divina. Asimismo, el filósofo Atahualpa - usando una máscara occidental- asume un papel docente basado en los principios de la razón y religión occidentales para (de)mostrar que los mismos peninsulares, a pesar de estar conscientes de sus errores, siguen cometiendo iniquidades para satisfacer su codicia porque "el oro" - hay que recordar a Colón - "nace" en estas tierras (Colón, 1992: 32) ${ }^{20}$.

Frente a esta lógica implacable como efectiva, y debido a que las arbitrariedades y crueldades de conquistadores y encomenderos no pueden ser defendidas, Fernando VII recurre al auxilio de la religión mediante un argumento ad verecundiam: afirma que sus derechos sobre las tierras americanas fueron establecidos por el papa Alejandro $\mathrm{VI}^{21}$. La referencia parece trivial. No. En la época era la piedra angular de la legitimidad española sobre sus colonias americanas $^{22}$. Incluso Bartolomé de Las Casas, de cuyas simpatías "indianas" no pueden dudarse, escribe, contraponiéndose a Vitoria ${ }^{23}$.

Los reyes de Castilla y León son verdaderos príncipes soberanos e universales señores y emperadores sobre muchos reyes, e a quien pertenesce de derecho todo aquel imperio alto e universal jurisdicción sobre todas las Indias, por la autoridad, concesión y donación de la dicha Santa Sede Apostólica, y así, por autoridad divina [...] son casi legados y coadjutores de la Sede Apostólica [...] ministros e instrumentos e medios idóneos (Hanke et al., 1965: 1033).

Tales ideas, con mayor o menor énfasis, eran compartidas por quienes creían en el rol providencialista de España en las Indias occidentales. Juan de Solórzano Pereira, por ejemplo, afirma en Política indiana (1648) que Dios ha escogido a España para llevar la fe cristiana al nuevo mundo. Pero es en el ámbito jurídico donde la "justificación" de la posesión de las Indias alcanza niveles "revisionistas" absurdos de manipulación y respaldo oficiales. Entre 1565 y 1570 Francisco de Toledo, Virrey de Perú, alentó la producción de "historias" que negaban la legitimidad del imperio del Tahuantinsuyo. El título de algunos capítulos me exime de cualquier comentario: "Del govierno y tiranias de los Ingas y como no heran Reyes naturales del Perú", "De como entraron los españoles en el Reyno del Perú y como fue justamente ganado y tiene su Majestad justo título á él" (Matienzo, 1910) ${ }^{24}$.

No obstante, la "validez" del argumento de Fernando VII en la época colonial, el Inca Atahualpa no se deja sorprender y tiene lista una 
defensa brillante. En efecto, aprovechando esta aparente legitimidad, atractiva para las masas americanas por su devoción a la religión católica, desarrolla una jurisprudencia contestataria al servicio de la emancipación:

Venero al Papa como a cabeza universal de la Iglesia, pero no puedo menos que decir que debió ser de una extravagancia muy consumada cuando cedió y donó tan francamente lo que teniendo propio dueño, en ningún caso pudo ser suyo, especialmente cuando Jesucristo, de quien han recibido los Pontífices toda su autoridad y a quien deben tener por modelo en todas sus operaciones, les dicta que no tienen potestad alguna sobre los monarcas de la tierra, o que a lo menos no conviene ejercerla, cuando dice: "mi Reino no es de este mundo". Cuando a sus apóstoles les enseña y encarga que veneren a los reyes y paguen los tributos al César (Monteagudo, 1974: 63-64).

Además de astuto teólogo, Atahualpa razona igual que un docto y experimentado abogado de Charcas. Critica no a la iglesia como institución sino al papa Borgia, uno de sus representantes más cuestionados por la historia ${ }^{25}$. La crítica es diplomática y certera: parte de las enseñanzas del evangelio, origen de la religión católica, que priorizan la espiritualidad y no los asuntos seculares. A continuación, Atahualpa desarrolla una disertación sobre los derechos naturales del hombre, reflejando la influencia de Rousseau en la profundidad de su pensamiento político. La importancia de esta sección, empero, radica en acusar a reyes "ociosos" de incumplimiento de deberes y, por esto, de quebrar el lazo de obediencia y sometimiento de sus súbditos:

El espíritu de la libertad [ha] nacido con el hombre, [el cual], libre por naturaleza, ha sido señor de sí mismo desde que vio la luz del mundo. Sus fuerzas y derechos en cuanto a ella han sido siempre imprescriptibles, nunca terminables o perecederos; si obligado a vivir preso en sociedad, ha hecho el terrible sacrificio de renunciar el derecho de disponer de sus acciones y sujetarse a los preceptos $\mathrm{y}$ estatutos de un monarca, no ha perdido [el derecho] de reclamar su primitivo estado o de mirar en su dependencia el móvil de su desgracia, y mucho menos cuando el despotismo, lo violenta y la coacción lo ha obligado a obedecer una autoridad que detesta y un señor a quien fundamentalmente aborrece porque nunca se le oculta que si le dio jurisdicción sobre sí y se avino a cumplir sus leyes y obedecer sus preceptos, ha sido precisamente bajo de la tácita y justa condición de que aquél mirara por su felicidad; por lo consiguiente, desde el mismo instante en que un monarca, piloto adormecido en el regazo del ocio o del interés, nada mira por el bien de sus vasallos, faltando él a sus deberes, ha roto también los vínculos de sujeción y dependencia de sus pueblos. Este es el sentir de todo hombre justo y la opinión de los verdaderos sabios (Monteagudo, 1974: 67-68).

Miguel de Cervantes (1998) habría aprobado estos juicios del "caballero de los cuatro confines"26: la libertad es un don de la naturaleza y, por eso, - repitiendo a Rousseauinalienable ${ }^{27}$. A veces, sin embargo, es el precio "terrible" que se paga para vivir en sociedad (otro eco del Contrato social). Mas si un soberano "adormecido" no cumple con sus funciones de proveer un buen gobierno, sus súbditos pueden —enseña el monarca inca - recuperar legítimamente su independencia jurídica. En el proceso de la emancipación latinoamericana, la afirmación de la libertad como don individual se subordinó al de las liberaciones nacionales por la influencia de liderazgos locales interesados en el control de un territorio geográficamente limitado: "América" en pedacitos.

El desenlace del Diálogo es previsible: el joven e inexperto rey de España, persuadido por los argumentos del Atahualpa independentista, exclama: "Convencido de tus razones, cuanto habéis dicho confieso y en su virtud, si aún viviera, yo mismo los moviera [a los americanos] a la libertad e independencia más bien que a vivir sujetos a una nación extranjera" (Monteagudo, 1974: 70). Triunfo y esplendor del Diálogo: en los Campos Elíseos -el lugar "perfecto" del imaginario europeo-, Fernando VII se transforma en un protomártir más de la independencia americana. He aquí el meollo del asunto: demostrar a la sociedad de Charcas (especialmente a los peninsulares y a sus partidarios) que la libertad y el derecho de autodeterminación de los pueblos son valores inalienables $\mathrm{y}$, en tanto tales, reconocidos por toda persona culta y noble, por encima de sus intereses materiales o políticos. Con el sustento 
de este andamiaje verbal, Atahualpa, después de convencer al soberano español de la justeza de su causa, termina su intervención con una apasionada proclama independentista ${ }^{28}$ :

HABITANTES DEL PERÚ: si desnaturalizados e insensibles habéis mirado hasta el día con semblante tranquilo y sereno la desolación e infortunio de vuestra desgraciada patria, recordad [despertad] ya del penoso letargo en que habéis estado sumergidos; desaparezca la penosa y funesta noche de la usurpación y amanezca el claro y luminoso día de la libertad. Quebrantad las terribles cadenas de la esclavitud y empezad a disfrutar de los deliciosos encantos de la independencia. Sí, paisanos: vuestra causa es justa, equitativos vuestros designios. Reuníos pues y corred a dar principio a la grande obra de vivir independientes (Monteagudo, 1974: 71).

El final del Diálogo - la derrota simbólica de España por América mediante la razón- es el resultado de la dialéctica del Inca sabio. Sus argumentos, incluidos los reparos de Fernando VII, conducen a lo que muchos querían y pocos temían: la independencia.

\section{Conclusiones}

El Diálogo entre Atahualpa y Fernando VII en los Campos Elíseos es un texto literario, jurídico y filosófico imprescindible para comprender las ideas independentistas en la entonces Real Audiencia de Charcas. Su planteamiento es claro y radical: la emancipación americana del dominio español. Esta coherencia ideológica es resultado de las numerosas rebeliones indígenas, del descontento de criollos y mestizos postergados y, sobre todo, la construcción simbólica de una nueva identidad propuesta por el incaísmo en torno a dos "naciones" antagónicas: "América" y España.

El incaísmo, el primer "nacionalismo" americano, ofrecía a la sociedad colonial descontenta la posibilidad de "retornar" y construir una "nación" americana, actualizando la tradición incaica (histórica y simbólica) con la ilustración europea. El Diálogo, una especie de pasquín para letrados, recoge y continúa esta tradición enriqueciéndola con ideas del
Contrato social. (Re)produce, de este modo, un discurso antiguo pero "nuevo" donde la libertad y la autodeterminación son derechos inalienables de los pueblos. La originalidad de este texto, además de ilustrar las relaciones entre política y literatura en el período colonial, radica en legitimar la independencia a partir de un hipotético diálogo entre dos monarcas víctimas, a su vez, de una agresión extranjera (España y Francia). La comparación dialéctica de las "desdichas" de ambos soberanos permite llegar a la independencia como algo no solo deseable sino inevitable. Así, de un espacio simbólico privado (conversación entre dos personas), el Diálogo pasa a controlar el espacio público charqueño con una conclusión previsible: la derrota simbólica de España por "América".

La importancia del Diálogo no se redujo al ámbito teórico. Al contrario, fue inmensa para los movimientos independentistas de Argentina (Buenos Aires) y Bolivia (Chuquisaca, La Paz y Cochabamba $)^{29}$. No se le otorga, sin embargo, la importancia que merece, puesto que no hay ni una edición crítica de este alegato tan coherente para justificar el movimiento de emancipación de "América". Otrosí — añadiría Monteagudo-, y los críticos no dicen nada sobre esto, es uno de los pocos documentos coloniales que ofrece una perspectiva transculturada de su contexto histórico ${ }^{30}$. En efecto, no solo rescata y prolonga la herencia cultural indígena, sino que también la conjuga con la ilustración europea: tradición y cambio se entrelazan en sus páginas para construir otra historia donde el hado iba a ser propicio $^{31}$.

La originalidad y el carácter subversivo del Diálogo son innegables. No es de extrañar que el joven Bernardo Monteagudo - su supuesto autor- experimentara la prisión identificado como un peligro para una sociedad colonial que empezaba a vivir sus "últimos días".

\section{Notas}

1. Bolivia, junto a Perú -y más que Ecuador-, es considerada (y se considera) una "nación incaica". Los incas, empero, sometieron a numerosos grupos 
indígenas del Collasuyo, región occidental que abarcaba menos del $25 \%$ de su actual territorio.

2. Un ejemplo es el poema canónico de la independencia: "A la victoria de Junín: canto a Bolívar" de José Joaquín Olmedo, poeta ecuatoriano-peruano.

3. Ver el ensayo de Díaz-Caballero (2005).

4. Tal vez por eso, el incaísmo, de forma intermitente, vuelve una y otra vez. Se notan sus resabios, por ejemplo, en el discurso anti-norteamericano de producciones literarias modernistas (Rubén Darío) y de vanguardia (Pablo Neruda y Ernesto Cardenal). A nivel político e ideológico la utopía arcaica está más viva que nunca en la zona andina. Alejandro Toledo y Ollanta Humala se presentan, en Perú, como sucesores de Pachacútec, el Inca que "sacude la tierra". En Bolivia, Evo Morales, quien no habla ningún idioma nativo, se considera el primer presidente "indio".

5. Es interesante notar que, en la mayoría de los casos, los sectores dirigentes del movimiento de emancipación, "descubren" a Garcilaso a través de sus lecturas europeas.

6. Los pasquines son considerados como los precursores de la prensa escrita. Sobre su importancia en el régimen colonial consultar los trabajos de Cornejo Quesada (2012); Revilla Orías (2009); Torrico Panozo (1997); y Vázquez Machicado (1988).

7. La comunidad imaginada, concepto de Benedict Anderson (1963), explica que una nación es una comunidad imaginada socialmente por las personas que se perciben a sí mismas como parte de esta construcción.

8. De prócer olvidado, Bernardo Monteagudo, se ha transformado en una figura canónica. Ver las obras de Echagüe (1950); Galván Moreno (1950); Herrero (2006); O’ Donell (1998); Vázquez Villanueva (2006); Vedia y Mitre (1950); y Villareal Brasca (2009).

9. Estas instituciones eran el "semillero" intelectual de los movimientos de emancipación en las colonias de España. Ver los trabajos de Francovich (1948); y Thibaud.

10. Bolivia, según su constitución política más reciente (2009), es un "estado plurinacional".
11. La precisión es insoslayable: Garcilaso es "nacionalista". Para él, el Cuzco es el centro (y sinónimo) del imperio de los incas: no así el reino de Quito, patria del "astuto" y "cruel" Atahualpa (consultar el Libro Nono, caps. XXXIII-XXXIX).

12. Uno de los significados del nombre de Cápac Yupanqui en quechua. Otros favorecen la traducción de "poderoso contador" (en sentido de numerar o contabilizar).

13. Atahualpa, Atabalipa o Atahuallpa (Atau-wallpa: gallo en quechua), es el decimotercero, y para muchos, último soberano inca. Después de vencer a su hermano Huáscar cerca del Cuzco (1532) se coronó Sapa Inca (emperador). Su reinado no duró mucho. Fue capturado por los españoles el 16 de noviembre de 1532 quienes, después de acusarle de idolatría, fratricidio, poligamia e incesto, le hicieron ejecutar por unos indios cañaris el 26 de julio de 1533 en la plaza de Cajamarca. Su muerte generó el mito de Inkarri.

14. Fernando VII (de Borbón). Rey de España, llamado el Deseado y también el rey Felón (1784-1833). Hijo y sucesor de Carlos IV y de María Luisa de Parma, fue rey entre marzo y mayo de 1808 y, tras la expulsión de José I Bonaparte, desde diciembre de 1813 hasta su muerte.

15. De acuerdo con Moreno (1997): "El silogismo con que los Doctores hicieron la revolución altoperuana, y cuya fuerza peripatética hizo saltar a la arena pública a todos los audaces de su gremio y a no pocos tímidos incautos fue el siguiente: Mayor: El vasallaje colonial es tributo debido no a España sino a la persona del legítimo rey borbónico de España; - Menor: Es así que nuestro legítimo y recién jurado Rey Señor natural Don Fernando VII abdicó junto con toda la familia borbónica de España y ya "no volverá": - Consecuencia: Luego la monarquía está legal y definitivamente acéfala por vacancia del trono, debe ser desobedecido el rey Bonaparte o cualquier otro que España quiera darse, deben cesar en sus funciones los actuales delegados y mandatarios de la extinta autoridad soberana, y deben en este caso proveer por sí mismas las provincias altas a su propio gobierno supremo, con calidad de POR AHORA, mientras no constare auténticamente la muerte de nuestro amado rey Fernando VII, y hasta que se presente legítimo sucesor al señorío de estas Américas. La aplicación positiva que se divisa al través de toda esta escolástica no debería ser otra que esta: De España, independencia completa luego al punto" (p. 403-4). 
16. Atahualpa es representado como un intelectual europeo: habla español y latín, está al tanto de las teorías políticas europeas, la historia mundial le es familiar, conoce la doctrina cristiana y sabe debatir como un doctor de Charcas.

17. Calificar de "tierno joven" a Fernando VII tiene el propósito de presentar a un Inca sabio con mucha experiencia que puede "convencer" e "instruir" al soberano español. No hay que olvidar que el espacio donde se desarrolla el diálogo son los Campos Elíseos donde, de acuerdo al tiempo histórico, Atahualpa llegó primero: tiene más antigüedad.

18. Los textos más citados de la literatura alternativa son los de Alvarado Tezozómoc (1980); Cussi Yupangui (1985); Guamán Poma de Ayala (1980); León Portilla (1959); y Santacruz Pachacuti Yamqui Salcamaygua (1968).

19. Se trata de otro capítulo de la desmitificación de los estereotipos de la conquista.

20. Informa a V. A.: “[...] y también aquí nace el oro que traen colgado a la nariz; mas, por no perder tiempo quiero ir a ver si puedo topar a la isla de Cipango" (Colón, 1992: 32).

21. Mediante la bula Inter-Caetera (1493) que entrega los territorios del Nuevo Mundo a Castilla y León: “[...] os donamos concedemos y asignamos perpetuamente, a vosotros y a vuestros herederos y sucesores en los reinos de Castilla y León, todas y cada una de las islas y tierras predichas y desconocidas que hasta el momento han sido halladas por vuestros enviados, y las que se encontrasen en el futuro y que en la actualidad no se encuentren bajo el dominio de ningún otro señor cristiano, junto con todos sus dominios, ciudades, fortalezas, lugares y villas, con todos sus derechos, jurisdicciones correspondientes y con todas sus pertenencias; y a vosotros y a vuestros herederos y sucesores os investimos con ellas y os hacemos, constituimos y deputamos señores de las mismas con plena, libre y omnímoda potestad, autoridad y jurisdicción. Declarando que por esta donación, concesión, asignación e investidura nuestra no debe considerarse extinguido o quitado de ningún modo ningún derecho adquirido por algún príncipe cristiano. $\mathrm{Y}$ además os mandamos en virtud de santa obediencia que haciendo todas las debidas diligencias del caso, destinéis a dichas tierras e islas varones probos y temerosos de Dios, peritos y expertos para instruir en la fe católica e imbuir en las buenas costumbres a sus pobladores y habitantes, lo cual nos auguramos y no dudamos que haréis, a causa de vuestra máxima devoción y de vuestra regia magnanimidad" (citado por Remeseiro Fernández, 2011: 6).

22. La bibliografía sobre este tema es extensa. Consultar el volumen V del Anuario mexicano de la historia del derecho (1993).

23. Francisco de Vitoria, apoyado en argumentos jurídicos, negaba el derecho de la autoridad papal para disponer de los estados de los príncipes y monarcas seculares.

24. Capítulo primero y segundo de Juan de Matienzo (1910), Gobierno del Perú [1567].

25. Alejandro VI (Roderic de Borja, 1431-1503) es uno de los papas más controvertidos. Practicó el nepotismo y tuvo relaciones sexuales con varias mujeres, en especial con Vannoza Cattanei, madre de César, Juan, Lucrezia y Jofré. También ha sido acusado de simonía por disponer de las riquezas de las iglesias y diaconías que ocupó para comprar el papado. La "leyenda Negra de los Borgia" asegura que Rodrigo Borgia, el papa más inmoral, obtuvo el pontificado por un escaso margen en la requerida mayoría de dos tercios: su propio voto.

26. Dice don Quijote: “-La libertad, Sancho, es uno de los más preciosos dones que a los hombres dieron los cielos; con ella no pueden igualarse los tesoros que encierra la tierra ni el mar encubre; por la libertad así como por la honra se puede y debe aventurar la vida, y, por el contrario, el cautiverio es el mayor mal que puede venir a los hombres" (Quijote, II, 58: 1094).

27. En el Contrato social de Rousseau se lee que: "Renunciar a la libertad es renunciar a la cualidad de hombres, a los derechos de humanidad e incluso a los deberes. No hay compensación posible para quien renuncia a todo. Tal renuncia es incompatible con la naturaleza del hombre, e implica arrebatar toda moralidad a las acciones el arrebatar la libertad a la voluntad. Por último, es una convención vana y contradictoria al reconocer, de una parte, una autoridad absoluta y, de otra, una obediencia sin límites" (1980: 37).

28. El final del Discurso muestra que su autor conocía muy bien los preceptos de la retórica, ya que es un ejemplo de la tópica de la conclusión: "El final de un discurso debía resumir los puntos principales 
y dirigirse después a los sentimientos del oyente, es decir, moverlo a indignación o a compasión" (Curtius, 1955: 136).

29. Junto a Pueblo enfermo de Alcides Arguedas (1979) y Creación de la pedagogía nacional de Franz Tamayo (1944), es la obra que mayor influencia política tuvo en la hoy república de Bolivia.

30. Transculturación es un concepto desarrollado por el antropólogo cubano Fernando Ortíz (2002). Se utiliza mucho en estudios de antropología, etnología, estudios culturales, etc. Para una comprensión del término desde un punto de vista literario, consultar Rama (1982).

31. Alusión a la primera línea del himno nacional de Bolivia: "Bolivianos: el hado propicio".

\section{Referencias bibliográficas}

Alvarado Tezozómoc, Fernando. 1980. Crónica mexicana. Orozco y Berra (ed). México, D. F.: Editorial Porrúa.

Anderson, Benedict. 1963. Comunidades imaginadas: reflexiones sobre el origen y la difusión del nacionalismo. México, D. F.: Fondo de Cultura Económica.

Annio, Antonio y François-Xavier Guerra. (Coords.). 2003 Inventando la nación. Iberoamérica siglo XIX. México, D. F.: Fondo de Cultura Económica.

Arguedas, Alcides. 1979. Pueblo enfermo. ( $3^{\mathrm{a}}$ ed.). La Paz: Isla.

Castañón Barrientos, Carlos. 1974. El "Diálogo" de Bernardo Monteagudo. La Paz: Empresa Editora Universo.

Cervantes, Miguel de. 1998. Don Quijote de la Mancha. Barcelona: Instituto CervantesCrítica.
Colón, Cristóbal. 1992. Los cuatro viajes del Almirante y su testamento. Ignacio B. ANZOÁTEGUI (14 ${ }^{\mathrm{a}}$ ed.). México, D. F: Espasa-Calpe.

Cornejo Quesada, Carlos. 2012. "Los pasquines en el Perú (siglos XVIII y XIX)". En: Correspondencias \& Análisis. Lima (2): 187-199.

Covarrubias Orozco, Sebastián de. 1911. Tesoro de la lengua castellana, o española [1611]. New York: Hispanic Society of America.

Curtius, Ernest Robert. 1955. Literatura europea y edad media latina. Trad. Margit Frenk Alatorre y Antonio Alatorre. México, D. F.: Fondo de Cultura Económica.

Cussi Yupangui, Titu. 1985. Ynstruçion del Ynga don Diego de Castro Titu Cussi Yupangui para el muy ilustre señor el licenciado Lope García de Castro. Luis Millones (introd.). Lima: El Virrey.

Delannoi, Gil y Pierre André Taguieff. 1993. Teorías del nacionalismo. Barcelona: Paidós.

Delannoi, Gil. 1993. "La teoría de la nación y sus ambivalencias". En: Delannoi-Taguieff. Teorías del nacionalismo. Barcelona: Paidós: 9-17.

Díaz-Caballero, Jesús. 2004. "Nación y patria: las lecturas de 'Los comentarios Reales' y el patriotismo criollo emancipador". En: Revista de crítica literaria latinoamericana. Lima (59): 81-108.

Díaz-Caballero, Jesús. 2005. “El incaísmo como primera ficción orientadora en la formación de la nación criolla en las Provincias Unidas del Río de la Plata". En: A Contracorriente: Revista de Historia Social y Literatura en América Latina. Logroño (3.1): 67-113. 
Echagüe, Juan Pablo. 1950. Historia de Monteagudo. Buenos Aires: EspasaCalpe.

Francovich, Guillermo. 1948. El pensamiento universitario de Charcas y otros ensayos. Sucre: Universidad de San Francisco Xavier.

Galván Moreno, C. 1950. Monteagudo. Ministro y Consejero de San Martín. El genio sombrio de la Revolución Americana. Buenos Aires: Editorial Claridad.

Guamán Poma de Ayala, Felipe. 1980. El primer nueva corónica y buen gobierno. 3 vols. Murra y Adorno (eds.). Traducción del quechua: Jorge L. Urioste. México, D. F.: Siglo XXI.

Guerra, François-Xavier. 2003. "Introducción". Inventando la nación. Iberoamérica siglo $X I X$. México, D. F.: Fondo de Cultura Económica: 7-11.

Hanke, Lewis et al (comps.). 1965. Tratados. 2 vols. México, D. F.: Fondo de Cultura Económica.

Herrero, Fabián. 2006. Bernardo Monteagudo. Revolución, Independencia, Confederacionismo. Buenos Aires: Grupo Editor Universitario.

Hobsbawm, E. J. 1991. Naciones y nacionalismo desde 1780. Trad. Jordi Beltrán. Barcelona: Crítica.

León Portilla, Miguel (ed.). 1959. Visión de los vencidos: relaciones indígenas de la conquista. México, D. F.: UNAM.

Lewis, Boleslao. 1943. Tupac Amaru. El rebelde. Buenos Aires: Editorial Claridad.
Lienhard, Martín. 1991. La voz y su huella. Escritura y conflicto étnico-social en América latina 1492-1988. Hanover, NH: Ediciones del Norte.

Matienzo, Juan de. 1910. Gobierno del Perú [1567]. Buenos Aires: Facultad de Filosofía y Letras.

Monteagudo, Bernardo. 1974. Diálogo entre Atawallpa y Fernando VII en los Campos Elíseos [1809]. Castañón Barrientos (ed.). La Paz: Empresa Editora Universo.

Moreno, Gabriel René. 1997. Últimos días coloniales en el Alto Perú. La Paz: Librería Editorial Juventud.

O’ Donnell Pacho. 1998. Monteagudo. La pasión revolucionaria. Buenos Aires: Planeta.

Ortíz, Fernando. 2002. Contrapunteo cubano del tabaco y el azúcar [1940]. SANTí (ed.). Madrid: Cátedra.

Rama, Ángel. 1982. Transculturación narrativa en América latina. México, D. F.: Siglo veintiuno editores.

Rama, Ángel.1984 La ciudad letrada. Hanover, NH. Ediciones del Norte.

Real Académia Española. n.d. Diccionario de Autoridades [1726-1739]. Recuperado de http://web.frl.es/DA.html.

Remeseiro Fernández, Alejandro. 2011. "Bula Inter-Caetera de Alejandro VI (1493) y las consecuencias político-administrativas del descubrimiento de América por parte de Colón en 1492". Recuperado de http:// www.archivodelafrontera.com/wpcontent/uploads/2011/08/GAL012.pdf. 
Revilla Orías, Paula A. 2009. "Pasquines reformistas, pasquines sediciosos: aquellas hojas volanderas en Charcas (siglos XVIII-XIX)". En: Revista Ciencia y Cultura (22-23): 33-43.

Romero, José Luis y Luis Alberto Romero (eds.). 1977. Pensamiento político de la Emancipación (1790-1825). 2 vols. Caracas: Biblioteca Ayacucho.

Romero, José Luis. "Prólogo". En Pensamiento político de la Emancipación (1790-1825). 2 vols. Caracas: Biblioteca Ayacucho: IXXLIII.

Rousseau, Jean-Jacques. 1980. El contrato social. Madrid: Espasa-Calpe.

Santacruz Pachacuti Yamqui Salcamaygua, Joan de. 1968. "Relación de antigüedades deste reyno del Perú". En: Crónicas peruanas de interés indigena. Esteve BARBA (ed). Madrid: Atlas. Biblioteca de Autores Españoles CCIX: 279-319.

Tamayo, Franz. 1944. Creación de la pedagogía nacional. La Paz: Biblioteca Boliviana.

Thibaud, Clément. 1997. "La Academia Carolina de Charcas: una escuela de dirigentes para la independencia". En: El siglo XIX. Bolivia y América Latina. Barragán et al. (comps). La Paz: Muela del Diablo Editores: 48-51.

Thibaud, Clément y Andrés Orías Bleichner. 2010. La Academia Carolina y la independencia de América: Los abogados de Chuquisaca (1776-1809). Sucre: Editorial Charcas.

Torrico Panozo, Vitaliano. 1997. El pasquín en la independencia del Alto Perú. Puebla. Benemérita Universidad Autónoma de Puebla. México, D. F.: Plaza y Valdés.

UNAM. Instituto de Investigaciones Jurídicas. 1993. Anuario mexicano de la historia del derecho. Vol. V. México, D. F.

Vázquez Machicado, Humberto. 1988. "El pasquinismo sedicioso y los pródromos de la emancipación en Charcas". En: Obras completas. Vol. III. La Paz: Don Bosco: 201-239.

Vázquez Villanueva, Graciana. 2006. Revolución $y$ discurso. Un portavoz para la integración hispanoamericana: Bernardo Monteagudo (1809-1825). Buenos Aires: La isla de la luna.

Vedia y Mitre, Mariano de. 1950. La vida de Monteagudo. Buenos Aires: Editorial Kraft.

Vega, Inca Garcilaso de la. 1991. Comentarios reales de los incas. Miró Quesada (ed). $\left(3^{\mathrm{a}}\right.$ ed.). 2 tomos. Caracas: Biblioteca Ayacucho.

Villareal Brasca, Amorina. 2009. "Bernardo de Monteagudo. Un americano revolucionario singular". En: Revista Complutense de Historia de América. Madrid (35): 285-293.

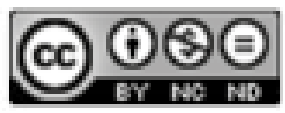

Este obra está bajo una licencia de Creative Commons Reconocimiento-NoComercial-SinObraDerivada 4.0 Internacional. 